\title{
The association between medical spending and health status: A study of selected African countries
}

\author{
Murad Bein ${ }^{1}$, Elizabeth Y. Coker-Farrell ${ }^{2}$
}

1. Department of Accounting and Finance, Faculty of Economics and Administrative Sciences, Cyprus International University

2. Department of Business Administration, Faculty of Economics and Administrative Sciences, Cyprus International University

\begin{abstract}
Background
Abstract

The report from the World Health Organization (WHO) reveals that health spending worldwide remains highly unequal as more than $80 \%$ of the world's population live in low and middle-income countries but only account for about $20 \%$ of global health expenditure. Another report by the WHO on the state of health financing in Africa published in 2013 intimates that countries that are part of their member states are still on the average level in meeting set goals in financing key health projects.

Objective

The study set out to investigate the association between public and private spending and health status for eight selected African countries, namely Burundi, Eritrea, Ethiopia, Kenya, Rwanda, Sudan, Tanzania and Uganda. Health status indicators include the incidence of tuberculosis, mortality rates, maternal deaths and prevalence of HIV.

Methods

Descriptive statistics and pairwise correlation are used to assess the relationship between healthcare spending and health status. Random and fixed effect models are further employed to provide insights into the association between descriptive statistics and pairwise correlation. We used annual data from the year 2000 to 2014 obtained from world development indicators.

Results

The relationship between healthcare spending (public and private) and health status is statistically significant. Public healthcare expenditure has a higher association than private expenditure in reducing the mortality rate, tuberculosis and HIV for the average country in our sample. For example, an increase in public healthcare spending is negatively associated and statistically significant at $5 \%$ or better in reducing female mortality, male mortality, tuberculosis and HIV. Private healthcare spending is more impactful in the area of maternal deaths, where it is associated negatively and statistically significant at $1 \%$. An increase in private healthcare spending is linked to a reduction in maternal deaths. We also compared the association between an increase in healthcare spending on males versus females and observed that public health expenditure impacts the health status of both sexes equally, however, private health expenditure provides a greater positive benefit to males. It is worth remembering that two goals of the United Nations agenda on sustainable development are gender equality and ensuring healthcare for all.

Conclusion

The findings of this research call for the selected African countries to pay more attention to public healthcare expenditure in order to improve health status, especially since private healthcare which provides access to healthcare facilities for some poor people leads to costs that are a burden. So, future research should focus on analyzing components of private healthcare spending such as direct household out-of-pocket spending, private insurance and direct service payments by private corporations as dependent variables to understand what form of private investment should be encouraged.
\end{abstract}

Keywords: healthcare expenditure, mortality rate, maternal deaths, HIV, tuberculosis, African countries.

\section{Introduction}

It is important for policy makers to understand that allocating more funds to healthcare spending is associated with improvements in health outcomes. In fact, if funds are allocated to building healthcare facilities in rural areas where there had been no access, and efforts are made to reduce waiting time in hospitals, a significant heath outcome will result. Equally, an increase in government expenditure for preventive or curative care, nutrition activities, emergency aid and immunization are expected to have a considerable effect on reducing mortality. Consequently, questions remain about the relationship between health spending and health outcomes, especially with rising healthcare costs. In this study, total healthcare expenditure is disaggregated into public and private healthcare expenditure (both as percentages of gross domestic product). Public healthcare expenditure consists of recurrent and capital spending from government budget and from external borrowing and grants, as well as from social health insurance funds. Private healthcare expenditure includes direct, household out-ofpocket spending, private insurance, charitable donations and direct service payments by private corporations ${ }^{1}$. According to the WHO, public health expenditure is higher in advanced and middle-income countries, and in low-income countries private healthcare expenditure is higher. This reveals that out-of-pocket expenditure makes up the largest proportion of private health expenditure. In fact, high out-of-pocket expenditure may create a burden for households to access healthcare services, which is a primary issue in third-world countries $^{2}$. 
Over the past 15 years, both public and private healthcare expenditure has risen in the eight African countries examined in this study. This increase in spending has corresponded with an improvement in several health status indicators. Table 1 shows the change in health status indicators and healthcare expenditure for eight African countries from 2000 to 2014. In almost all the countries, there has been a reduction in the mortality rate, maternal deaths, prevalence of HIV and incidence of tuberculosis. The highest reduction in female adult mortality was achieved in Tanzania (47\%), and the highest reduction in male adult mortality was achieved in Rwanda (50\%). Rwanda also experienced the highest reduction in maternal deaths $(65 \%)$. The highest reduction in the incidence of tuberculosis was observed in Uganda $(62 \%)$. The prevalence of HIV has been reduced in most of the countries, with the highest reduction in Burundi $(0.67 \%)$. It is worth mentioning that this selected Africa region experiences civil and cross-border war. Most of the eight selected countries have witnessed either political turmoil or civil war in the past. Due to missing information, we did not include countries such as Djibouti, Somalia or South Sudan. The government and policy makers of the eight countries included in this study paid little or no attention to the development of their health sector in the past due to having to focus attention on resolving political instability, social security issues and various other crises. Today, the story is changing as these governments and policy makers are seen to be striving to improve and allocate more funds to the health sector for proper growth and development of the sector. For example, looking at Table 1, there has been a greater change in healthcare expenditure and health outcomes for almost all countries except Eritrea, where total healthcare expenditure declined, and progress in health outcomes was recorded. Most of the countries in our research study do not have enough capacity to raise funds publicly as revenues due to their informal running system, which makes collection of the tax very difficult, hence limiting and causing serious constraints on healthcare investments. Therefore, for this gap to be bridged, the government must prioritize the allocation of resources through innovative means towards healthcare spending. Although external aids and funds remain very relevant in all aspects, the government must ensure effective and improved flows of funds by harmonizing resource allocation towards health spending as a national priority ${ }^{3}$. We believe it is necessary to examine the effect of healthcare expenditure, and this study aims to use empirical work to provide evidence of an association between healthcare expenditures and health outcomes, positive or negative. Without doubt, Sub-Saharan Africa is one of the most affected regions in mortality and HIV incidence in the world. It is critical for governments in these countries and health sector strategists to understand to what extent health expenditure must increase to bring the desired health outcomes ${ }^{4}$.

A growing body of empirical and conceptual studies examine the relationship between healthcare spending and health status, however, a consensus has not been reached. Among these studies, some researchers consider total healthcare expenditure as a determinant of health status, while other researchers concentrate on its components: public health expenditure and private health expenditure. Anton and Onofrei ${ }^{4}$ used the Ordinary Least Squares (OLS) method to study the relationship between total healthcare expenditure and under-five mortality rates for Central and
Eastern European countries. Their study showed that a one percentage point increase in total expenditure is associated with a $0.64 \%$ reduction in the under-five mortality rate. Anyanwu and Erhijakpor ${ }^{5}$ examined the relationship between total health expenditure and public healthcare expenditure on health outcomes (infant and under-five mortality). Their study revealed that for Sub-Saharan African countries, there is a positive and significant association with infant and under-five mortality. Heijink et al. ${ }^{6}$ studied the relationship between private and public health expenditure for 14 Western countries for the period 1996 to 2006 and argued that total healthcare expenditure is associated with reducing avoidable mortality. Other researchers have studied the relationship and provide evidence that there is a positive association ${ }^{7-14}$. Nevertheless, some researchers argue that there is no relationship. For example, a study by Lippi et al. ${ }^{15}$, investigating the association between healthcare expenditure and mortality rates for the European Union using the Spearman correlation method, revealed there is no relationship between healthcare expenditure and mortality rates. In line with this finding, Mackenbach ${ }^{16}$ documented that there is no association between healthcare expenditures and decreasing mortality rates. Along with this study, some researchers found statistically insignificant relations or documented limited relationships ${ }^{17-19}$.

A good amount of literature has explored healthcare expenditure by separating public and private healthcare spending. Several studies have suggested that public healthcare expenditure reduces mortality and increases life expectancy. ${ }^{20-25}$ Using an error correction model, researchers found that the relationship between public health expenditure and life expectancy in Lesotho was significant and positive as seen in the results of the life expectancy at birth (years), infant mortality rate (per 1,000 live births), and under-five mortality rate $(\text { per } 1,000)^{20}$. Bokhari and Gottret ${ }^{21}$ also showed that public healthcare expenditure positively contributed to a reduction in under-five mortality and maternal mortality. On the other hand, researchers showed that there is little to no relationship between public healthcare spending and health outcomes ${ }^{26-30}$.

Among these studies, Zakir and Wunnaya ${ }^{26}$ studied the relationship between public healthcare expenditure and mortality in 1993 for 117 countries. The researchers found that public healthcare expenditure does not have a major effect on reducing infant mortality rates. A study by Berger and $\mathrm{Messer}^{28}$, using a sample study running from 1960 to 1992 for 20 Organisation for Economic Co-operation and Development (OECD) countries, showed that an increase in public healthcare expenditure increases mortality rates. Filmer and Pritchett ${ }^{30}$ showed that government healthcare expenditure has a limited effect on under-five mortality.

Additionally, some studies consider the impact of private healthcare expenditure together with public expenditure ${ }^{31-36}$. Aisa et $\mathrm{al}^{31}$, showed that public healthcare expenditure has a higher impact on life expectancy than private expenditure. Homaie et al. ${ }^{34}$ carried out a panel study of Eastern Mediterranean countries and showed that while public healthcare expenditure has a negative impact on infant mortality, private expenditure has a positive impact. This study was limited, however, since only the variable of infant mortality was analyzed. Issa and Ouattara ${ }^{35}$ showed that total healthcare expenditure is negatively related to mortality, but when differentiating between public 
Table 1: Health Status and Healthcare Expenditure in Eight Selected African Countries

\begin{tabular}{|c|c|c|c|c|c|c|c|c|}
\hline Variable & Burundí & Erittea & Ethiopia & Kenya & Rwanda & Tanzania & Sudan & Uganda \\
\hline MRAF & 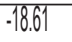 & .31 .88 & -44.48 & -44.70 & -42.06 & -46.80 & -20.51 & -43.00 \\
\hline MRAM & .14 .46 & -30.11 & .37 .56 & -37.33 & .50 .02 & .38 .85 & -20.10 & -36.35 \\
\hline NIMD & 25.00 & -4.17 & -53.85 & -9.89 & .055 .63 & -29.17 & .31 .15 & -19.44 \\
\hline $\mathrm{TU}$ & .56 .55 & .55 .93 & .50 .83 & .13 .99 & -35.71 & .34 .99 & -26.56 & .62 .30 \\
\hline PHIV & -0.67 & $\cdot 0.61$ & -0.63 & -0.46 & -0.47 & $\cdot 0.33$ & 1.00 & 0.01 \\
\hline HEPT & 0.034 & .36 .37 & 1.78 & -11.91 & 81.58 & 99.91 & 183.42 & 9.84 \\
\hline HEPP & 182.96 & -3.84 & 20.35 & 61.71 & 73.57 & 126.01 & 103.11 & -2.00 \\
\hline HE & 51.37 & -24.72 & 11.92 & 22.16 & 78.44 & 111.23 & 161.32 & 6.63 \\
\hline
\end{tabular}

Mortality rate, adult, female (per 1,000 female adults) (MRAF); Mortality rate, adult, male (per 1,000 male adults) (MRAM); Number of maternal deaths (NMD) (per 100,000 people)); Incidence of tuberculosis (per 100,000 people) (TU); Prevalence of HIV, (total \% of population age 15-49) (PHIV); HEPT (private healthcare expenditure), HEPP (Public healthcare expenditure) and Total Healthcare expenditures (HE).

Table 2: Descriptive Summary of Variables

\begin{tabular}{|l|l|l|l|l|l|}
\hline Variable & Obs & Mean & Std. Dev. & Min & Max \\
\hline HEPT & 120 & 3.429 & 1.735 & 1.48 & 7.96 \\
\hline HEPP & 120 & 2.36 & 0.9477 & 0.755 & 5.499 \\
\hline HE & 120 & 5.79 & 2.1 & 2.6 & 11.4 \\
\hline TU & 120 & 234 & 129 & 63 & 510 \\
\hline MRAF & 120 & 303 & 78 & 177 & 496 \\
\hline MRAM & 120 & 370 & 74 & 254 & 592 \\
\hline NIMD & 120 & 7108 & 5931 & 920 & 26000 \\
\hline PHIV & 120 & 3.65 & 2.66 & 0.1 & 9.9 \\
\hline
\end{tabular}

and private spending, they found that private healthcare expenditure has a greater impact on mortality than public healthcare expenditure.

The above researchers mostly considered healthcare expenditure and its components (public and private as a percentage of gross domestic product), however, there are those who focus on per capita healthcare expenditure. For instance, in 2008, Gani ${ }^{36}$ studied the relationship between per capita public healthcare expenditure and three health outcomes (infant and under-five mortality rates and crude death rate) for seven Pacific island countries using sample data from the period 1990 to 2002. His findings showed that a $10 \%$ increase in per capita healthcare expenditure is associated with a reduction of 3.6 infant deaths per 1,000 live births in a country with a high infant mortality rate. Others have also considered per capita public healthcare expenditure as a dependent health outcome ${ }^{37}$.

The existing literature also emphasizes that other variables can reduce child mortality rates with or without factoring in public healthcare expenditure ${ }^{38-41}$. Within this literature, the 1997 study by Filmer and Pritchett ${ }^{30}$ provided empirical support to demonstrate that public health spending is not a main driver in reducing child mortality rates. They added that variables such as income, income inequality, female education and cultural factors are important in explaining the variation in child mortality rates. In line with this, other researchers argued that factors to consider include education status of parents, females and children, and medical facilities (Kessler and McClellan ${ }^{42}$, Glied and LierasMuney $\left.{ }^{43}\right)$. Other researchers such as Moore ${ }^{44}$ showed that global trade and globalization reduced mortality. Wagstaff and Cleason $(2004)^{45}$ underline that good policy and institutional improvement provide an increase in the link between government healthcare expenditure and health outcomes (maternal mortality, underweight children, underfive mortality and tuberculosis).

Some researchers investigated how healthcare expenditure affects impoverishment and other variables. For example, Bredenkamp et al. ${ }^{46}$, using data from household surveys, examined the variation in out-of-pocket expenditure for healthcare and their relationship with financial protection for Western Balkans countries. Their findings demonstrated that individual healthcare spending significantly contributes to increased poverty and making the situation worse for those who are already impoverished. Some researchers have investigated the relationship between insurance coverage and/or out-of-pocket expenditure $\mathrm{e}^{47-50}$.

Based on the literature on healthcare expenditure and health outcomes, we can make the following summary. Existing literature reveals that the association between healthcare expenditure and health outcomes is still in debate: some report there is no relationship, while others report a limited relationship. Besides this, most of the literature focuses on non-African countries, even though the region is one of the most affected regions in the world. Studies that investigate public and private healthcare expenditure are very rare. Lastly, studies that examine the association between maternal deaths and the prevalence of HIV and health expenditure are limited, as most of the literature focuses on under-five mortality and mortality rates. Therefore, this paper adds to the body of available evidence on the relationship between healthcare expenditure and the following health variables: incidence of tuberculosis, male and female mortality rates, number of maternal deaths and the prevalence of HIV in eight selected African countries, and whether the contribution of public healthcare expenditure is more significant than private healthcare expenditure.

This study differs from the existing literature on healthcare spending and health outcomes in the following ways. First, we make use of time series and strong, balanced data to examine the association with a total of 112 observations. Second, previous research on African countries, such as the study by Anyanwu and Erhijakpor ${ }^{5}$, focuses on infant and under-five mortality. In this study, we paid attention to four health outcome variables, namely incidence of tuberculosis, adult mortality rate, number of maternal deaths per year and prevalence of HIV. The study also examines whether health spending has a different relationship based on gender; this is important to understand if females are equal to males in healthcare spending. According to Gao and $\mathrm{YaO}^{52}$, men have access to less health spending than women, although they earn more. Irving and Kingdom ${ }^{51}$, based on their interest in curative healthcare, made sequential observations on gender differences on healthcare based on health spending, state of health and consultation. Their results found: first, women tend to report states of ill health with higher frequency than men making their expenditure higher; second, women consult healthcare providers (doctors, physicians, etc.) more readily than men do, keeping them healthier; third, on consultation reports, the rate at which men and women incur positive health spending differs a lot and lastly, the average health spending analysis differs for women and for men.

According to global burden diseases (GBD) ${ }^{53} 2015$ report, mortality levels for individuals that are HIV infected have 
Table 3: Pairwise Correlation between Healthcare

\section{Expenditures and Health Status}

\begin{tabular}{|l|l|l|l|}
\hline & HEPT & HEPP & HE \\
\hline TU & -0.275 & -0.0115 & -0.226 \\
\hline LTU & -0.23 & -0.0152 & -0.192 \\
\hline MRAF & -0.019 & -0.1462 & -0.079 \\
\hline MRAM & 0.0363 & -0.0626 & 0.0017 \\
\hline NMD & -0.322 & 0.0759 & -0.226 \\
\hline LNMD & -0.141 & 0.1173 & -0.062 \\
\hline PHIV & 0.0866 & 0.0263 & 0.0813 \\
\hline
\end{tabular}

Note: LTU and LNMD are converted in to a logarithmic.

Table 4: Healthcare Expenditure and Mortality Rate

\begin{tabular}{|c|c|c|c|c|}
\hline & \multicolumn{2}{|c|}{ Pane $A$ : (HEPP and adult mortality rates } & \multicolumn{2}{|c|}{ Pane $\mathrm{B}$ : (HEPT) and adult mortality rates } \\
\hline & MRAF & MRAM & MRAF & MRAM \\
\hline & Random Effects & Fixed Effects & Random Effects & Fixed Effects \\
\hline MRAF\&MRAM & Coef & Coef & Coef & Coef \\
\hline HEP & $.0798^{* \star * \pi}$ & $.06827^{7 * *}$ & $\ldots$ & $\ldots$ \\
\hline & 0.0200 & 0.01811 & $\ldots$ & ... \\
\hline HEPT & $\ldots$ & $\ldots$ & $.0457^{* \star \star *}$ & $.05393^{3 * *}$ \\
\hline & -.. & ... & 0.0147 & 0131 \\
\hline Intercent & $5.872^{\star * \star}$ & $6.055^{* * \pi}$ & $5.840^{* * \pi}$ & $6.079^{* * \ldots}$ \\
\hline & 0905 & 0448 & 10922 & 0.0470 \\
\hline $\mathrm{R}-\mathrm{SO}$ & $0.129^{\circ}$ & 0.113 & $0.089^{\circ}$ & 0.131 \\
\hline F-statistics & & $14.17^{* * \pi}$ & & $1678^{* * *}$ \\
\hline Wald chi2 1 & $15.79^{* \star \star \pi}$ & & $9.66^{* \pi *}$ & \\
\hline $\begin{array}{l}\text { Hausman test } \\
\text { chi2 } \\
\text { prob>chi2 }\end{array}$ & $\begin{array}{c}0.67 \\
0.4121\end{array}$ & $\begin{array}{c}4.46 \\
0.0346^{* *}\end{array}$ & $\begin{array}{c}1.32 \\
0.2510\end{array}$ & $\begin{array}{c}7.82 \\
0.0052^{\text {*k* }}\end{array}$ \\
\hline
\end{tabular}

Note: $* * *, * *$, and $*$ are statistically significant at $1 \%, 5 \%$ and $10 \%$ respectively.

different mortality rates; for children, adult male and adult female for the affected population. The female HIV infected population are higher than the others according to Aaron et al. $^{54}$. Also, based on life expectancy, it was also observed that women live longer than men with a gap of 4.6 years approximately according to the Human Development Index ${ }^{55}$. It is worth remembering that two goals from the United Nations' (UN's) agenda for sustainable development are gender equality and ensuring healthy lives for all ${ }^{56}$. In addition, previous research highlights that the mortality rate is high among females and also that healthcare spending is different between genders ${ }^{57-59}$. Third, the existing literature did not investigate healthcare spending by separating public healthcare and private healthcare expenditures on health outcomes for selected African countries. This is important since the WHO reveals that in advanced and middle-income countries, public health expenditure is higher, whereas in low-income countries private health expenditure is higher.

The paper documents that there is a statistically significant association between healthcare spending (public and private) and health status. Public healthcare expenditure has a higher association with reducing the adult mortality rate, tuberculosis and HIV than private expenditure for the average country in our sample. We also compared the association between increases in healthcare spending on males versus females and observed that public health expenditure is equal, related to the health status of both sexes. However, private health expenditure provides a greater positive benefit for males. The remainder of this paper is organised as follows. Section Two discusses the data and methodology of the study, while Section Three presents the empirical results. Finally, some concluding remarks are offered.

\section{Data and Methodology}

\section{Data and descriptive statistics}

World development indicator yearly data from 2000 to 2014 is used for this study. Data before 2000 is not used as
HIV data for the Republic of Sudan is unavailable. Table 2 provides a descriptive summary of all the variables utilized in this study. Variables are defined as follows. HEPT: private healthcare expenditure as a percentage of GDP; HEPP: public healthcare expenditure as a percentage of GDP; HE: total healthcare expenditure as a percentage of GDP; TU: incidence of tuberculosis per 100,000 people; MRAF: female adult mortality rate per 1,000 female adults; MRM: male adult mortality rate per 1,000 male adults; NMD: number of maternal deaths per year; and PHIV: prevalence of HIV as a percentage of the population ages 15-49. Table 2 also provides characteristics of the data. For example, private healthcare expenditure as a percentage of GDP was highest in Burundi at $8 \%$ and lowest in Tanzania at 2\%. Public healthcare expenditure as a percentage of GDP was highest in Burundi at $6 \%$. The highest incidence of tuberculosis was found in Tanzania, at 510 per 100,000 people, while the lowest was at 63 per 100,000 people in Rwanda. The highest adult female mortality rate was in Uganda, at 496 per 1,000 people, and lowest in Rwanda at 178 per 1,000 people. For males, the highest adult male mortality was in Rwanda in 2000, at 593 per 1,000 people. This figure decreased to 296 by 2014 . The lowest male mortality rate was observed in Sudan, at 254 per 1,000 people. The highest number of maternal deaths per year was 26,000 in Ethiopia in 2014; by 2014, this figure decreased to 12,000. The lowest number of maternal deaths per year was found in Eritrea, at 920. In the year 2000 in Kenya, 9.9\% of the population was infected with HIV. This percentage dropped to $5.3 \%$ by 2014 . Sudan is least affected by HIV, with only $0.1 \%$ of the population infected. Table 3 shows the correlation between healthcare expenditure (total, public and private) as percentages of GDP, with several variables representing health status. Focusing on the first column, private healthcare expenditure has a negative relationship with almost all variables, with the greatest negative correlation observed with the number of maternal deaths. A positive correlation is observed with the prevalence of HIV and male mortality. This is likely because pairwise correlation does not consider variations over time or individual variations ${ }^{60-61}$. Considering the relationship between public healthcare expenditure and health status, a negative relationship is observed with almost all variables except the number of maternal deaths and prevalence of HIV. The greatest negative relationship is observed between adult female mortality and public healthcare expenditure. Total healthcare expenditure has a negative relationship with all variables except prevalence of HIV.

\section{Methodology}

To investigate the impact of public and private healthcare expenditure on health status for eight selected African countries, we utilized two different panel data techniques: fixed and random effects. We employed two methods since each technique has some advantages over the other. The fixed model has advantages over the random model since it accounts for individual country variation, and this is important since each of the eight countries in our sample has a different healthcare system, economic structure, demographics, etc. This model removes the effect of these time-invariant characteristics which allow us to assess the net effect of the predictor on the outcome variables. Also, this model assumes that the characteristics of the timeinvariant characteristics are specified to the individual, so should not have any relationship with another individual 
characteristic $^{62-64}$, the random method may be preferred over the fixed if it is believed that some variables are time-invariant and that dependent variables are random and uncorrelated with the dependent variable. Also, in random effects, we can estimate effects of the stable covariates like race and gender. Furthermore, because it uses a variation for both within as well as between individuals, the random effects technique typically has minimal sampling variability compared with fived effects ${ }^{62-64}$. Fixed and random models are suitable for this study since the data is cross-section and time series (for the eight countries and yearly data from 2000-2014). In addition, the study sample is strongly balanced data (no missing observation) with a total observation of 112. The above two methods have been used by several researchers in healthcare and social science to investigate cross-section and time series panel data. For example, researchers ${ }^{65} \& 66$ make use of the fixed-effect model ${ }^{65}$, while random methods were used by Akinci et $\mathrm{al}^{66}$. The Hausman test is carried out to choose between these two methods and mostly when the result differs. In our case, the two models yield the same results, hence this research carried out the Hausman test for each variable, and the results are reported in the empirical section. Other models such as pooled OLS are also used in healthcare and social science ${ }^{67}$. However, the model has drawbacks such as not taking heterogeneity into account ${ }^{62}$.

Models 1 and 2 represent the specific equations we used.

$$
\begin{aligned}
& \text { Model } 1 \\
& Y=\propto_{i}+\beta_{1} H E P P_{i t}+\varepsilon_{i t}
\end{aligned}
$$

$$
\begin{aligned}
& \text { Model } 2 \\
& Y=\propto_{i}+\beta_{1} H E P T_{i t}+\varepsilon_{i t}
\end{aligned}
$$

In the equations, $i$ and $t$ represent the number of countries and time, respectively. Y represents the dependent variables MRAF, MRM, NMD, TU and PHIV. HEPP and HEPT are the independent variables. $\alpha \alpha_{\mathrm{i}}$ is the fixed-effect parameter that varies across individual countries but does not vary over time. Under the random effect model, all countries have a common mean value for the intercept. $\varepsilon_{i t} \varepsilon_{i t}$ is the error term for each observation normally distributed with ' 0 ' mean and constant variance. ${ }^{62}$

\section{Empirical Results}

Two panel techniques, namely fixed and random model are used to investigate the relationship between healthcare expenditure and health outcomes. Regression results are reported in Tables 4 to 7 . In choosing which model to present we have carried out the Hausman test that is to test the null hypothesis. The random model is better against the alternative fixed model. The random model is said to be better if prob>chi2 is above $5 \%$ and whereas the fixed is better if prob $>$ chi2 is below 5\%. Nevertheless, in this study the estimation from both models yielded the same results and for this reason the output of the one model is reported. Table 4 displays the results of the empirical examination of public and private healthcare expenditure on adult female and male mortality. In Panel A, considering the association between public healthcare expenditure on female and male adult mortality using random and fixed effects models respectively, one can observe that a negative and robust relationship exists between them. The results are statistically significant at $1 \%$, and there is a negative association between both sexes' mortality rates and public health expenditure. In other words, if a country increases its public health expenditure, the result will be a decline in adult mortality. Referencing Panel B, exploring the relationship between private healthcare expenditure on adult female and male mortality using random and fixed effects models respectively, the results reveal there is a negative relationship that is statistically significant at $1 \%$ between the two variables. Although both public and private expenditure is negatively related and statistically significant at the $1 \%$ level, the association is observed much more with public expenditure considering the different effect of healthcare expenditure on adult female and male mortality. We observed public healthcare expenditure on female adult mortality to be greater than with male adult mortality, even though both are statistically significant at the 1\% level. However, private healthcare expenditure has a greater impact on male mortality than on female mortality. Table 5 illustrates the results from analyzing the impact of public and private healthcare expenditure with the number of maternal deaths. Both Panels A and B show a negative relationship between the variables. However, the relationship between private healthcare expenditure and maternal deaths is more robust and statistically significant. In Panel B, for example, an increase in private healthcare expenditure is associated with a decline in the number of maternal deaths, the result is statistically significant at 5\%. However, to understand what type private health expenditure should be encouraged, it is necessary to examine each component individually. Panel A also shows a negative association between public healthcare expenditure and maternal deaths. However, there is no statistical relationship. Additionally, the pairwise correlation test supports these results. The Hausman test reveals that the random method is better since prob>chi2 is above $5 \%$. Table 6 presents the results of the analysis of the impact of public and private healthcare expenditure on the prevalence of HIV as a percentage of the population age 15 to 49 . Empirical results illustrate a negative relationship between both public and private healthcare spending and HIV. Public expenditure, seen in Panel A, shows a more robust and higher association with reducing HIV prevalence than private expenditure. Panel B shows a negative association between private healthcare expenditure and the prevalence of HIV. Pairwise correlation does not support this negative relationship since it does not consider individual countries' variations; some countries have an extremely low rate of HIV while others have much higher rates. Pairwise correlation also does not consider time variations. The Hausman test reveals random is better since prob>chi2 is above $5 \%$.

Table 7 presents the results of the analysis of the impact of public and private healthcare expenditure on the incidence of tuberculosis per 100,000 people. The empirical evidence shows a strong negative and statistically significant relationship between healthcare expenditure and tuberculosis. Panel A shows that public healthcare expenditure has a higher association with tuberculosis than private expenditure. Therefore, a policy that increases public health expenditure is associated with a decline in tuberculosis per 100,000. Panel B shows the relationship between private healthcare expenditure and a reduction in tuberculosis per 100,000 people in the average country. The results reveal there is a negative relationship between private expenditure and tuberculosis. The beta coefficient for public expenditure is statistically significant at $1 \%$, and for private expenditure, it is significant at $10 \%$. Pairwise correlation also supports the 
Table 5: Healthcare Expenditure and Maternal Deaths

\begin{tabular}{|l|c|c|}
\hline & Panel A: HEPP and LNMD & Panel B: HEPT and LNMD \\
\hline & Random Effects & Random Effects \\
\hline LNMD & Coef. & Coef. \\
\hline HEPP & -0.0356 & -- \\
\hline & {$[0.0218]$} & -- \\
\hline HEPT & -- & $-0.0871^{* *}$ \\
\hline & -- & {$[0.014]$} \\
\hline Intercept & $8.578^{* *}$ & $8.793^{* * *}$ \\
\hline & {$[0.366]$} & {$[0.373]$} \\
\hline R-sq & 0.0238 & 0.02584 \\
\hline Wald chi2(1) & 2.66 & $39.07^{* * *}$ \\
\hline Hausman test & 0.08 & 0.09 \\
chi2 \\
prob>chi2
\end{tabular}

Note: $* * *, * *$, and $*$ are statistically significant at $1 \%, 5 \%$ and $10 \%$ respectively.

Table 6: Healthcare Expenditure and Prevalence of HIV

\begin{tabular}{|l|c|c|}
\hline & $\begin{array}{l}\text { Panel A: HEPP and prevalence } \\
\text { of HIV }\end{array}$ & Panel B: HEPT and prevalence of HIV \\
\hline & Random Effects & Random Effects \\
\hline HIV & Coef. & Coef. \\
\hline HEPP & $-0.412^{* * *}$ & -- \\
\hline & {$[0.089]$} & -- \\
\hline HEPT & -- & $-0.1384^{* *}$ \\
\hline & -- & {$[0.0702]$} \\
\hline Intercept & $4.632^{* * *}$ & $4.133^{* * *}$ \\
\hline & {$[1.037]$} & {$[1.049]$} \\
\hline R-sq & 0.1611 & 0.0351 \\
\hline Wald chi2 (1) & $21.11^{* *}$ & $3.88^{* *}$ \\
\hline $\begin{array}{l}\text { Hausman test } \\
\text { chi2 }\end{array}$ & 0.21 & 0.20 \\
prob>chi2 & 0.6468 & 0.6552 \\
\hline
\end{tabular}

Note: $* * *, * *$, and $*$ are statistically significant at $1 \%, 5 \%$ and $10 \%$ respectively.

Table 7: Healthcare Expenditures and Tuberculosis

\begin{tabular}{|c|c|c|}
\hline & Panel A: HEPP and tuberculosis & Panel B: HEPT and tuberculosis \\
\hline & Random Effects & Random Effects \\
\hline tuberculosis & Coef. & Coef. \\
\hline \multirow[t]{2}{*}{ HEPP } & $-0.1212{ }^{-0}$ & $\cdots$ \\
\hline & {$[0.024]$} & -- \\
\hline \multirow[t]{2}{*}{ HEPT } & -- & $-0.0351^{*}$ \\
\hline & . & {$[0.019]$} \\
\hline \multirow[t]{2}{*}{ Intercept } & $5.5866^{\prime \prime \prime}$ & $5.42^{* * *}$ \\
\hline & {$[0.222]$} & [0.220] \\
\hline R-sq & 0.179 & 0.0258 \\
\hline Wald chi2 (1) & $23.96^{* * x}$ & $3.21^{*}$ \\
\hline $\begin{array}{l}\text { Hausman test } \\
\text { chi2 } \\
\text { prob>chi2 }\end{array}$ & $\begin{array}{c}0.37 \\
0.5417\end{array}$ & $\begin{array}{c}0.13 \\
0.7202\end{array}$ \\
\hline
\end{tabular}

Note: $* * * * *$, and $*$ are statistically significant at $1 \%, 5 \%$ and $10 \%$ respectively.

negative relationship between healthcare spending and the incidence of tuberculosis. The Hausman test reveals that the random method is better since prob $>$ chi2 is above $5 \%$.

\section{Conclusion}

This study investigates the association between public and private healthcare expenditure on the health status of people in eight selected African countries. The study used yearly data from 2000 to 2014 and employed two popular methods, random and fixed effect. The empirical analysis resulted in several findings. There is a negative correlation between both public and private healthcare expenditure and incidence of tuberculosis, adult male and female mortality rates, maternal deaths and the prevalence of HIV. Comparing the impact of public and private healthcare expenditure to the quality of wellbeing, we found that public healthcare expenditure had a greater impact than private healthcare expenditure on all variables except for maternal deaths, where the impact of private expenditure was double that of public expenditure. The results are robust and statistically significant in nearly all regressions. In general, our findings reveal that an increase in public healthcare spending will lead to a reduction in female morality, male mortality, number of maternal deaths, incidence of tuberculosis and prevalence of HIV. We found private healthcare expenditure to be gender-sensitive, with male mortality being impacted more significantly than female mortality.

In conclusion, the above findings convey an essential policy message that should be considered by selected African countries. Our findings show that public healthcare spending improves health status, and it is therefore important for policy makers to pay attention to allocating funds to the healthcare sector. The above finding calls for the eight selected African countries to pay more attention to public healthcare expenditure in order to improve health status, especially since private healthcare creates an extra burden for the poor to access healthcare facilities. In this regard, future research should focus on analyzing components of private healthcare spending such as direct household out-of-pocket spending, private insurance and direct service payments by private corporations as dependent variables to understand what form of private investment should be encouraged. In addition, future research may also concentrate on investigating other health outcome variables for all SubSaharan African countries, using recent data and possibly include in the model the number of physicians, number of hospital beds and literacy rates.

\section{References}

1. World Health Organization (WHO). State of health financing in the African Region. [Internet]. 2017 June [Cited 2018 April 5]. Available from: $\quad$ http://www.afro.who.int/sites/default/files/2017-06/state-ofhealth-financing-afro.pdf.

2. World Health Organization (WHO). Global Health Expenditure Database [internet]. 2014 May [cited 2018 February 25] Available from: http://apps.who.int/nha/database.

3. World Health Organization (WHO). Global health sector response to HIV, 2000-2015: Focus on innovations in Africa. Geneva: WHO. 2015 November [cited 2017 October 6]. Available from: http://www.who. int/hiv/pub/progressreports/2015-progress-report/en/.

4. Anton SG, Onofrei M. Healthcare Performance and Health Financing Systems in Countries from Central and Eastern Europe. Transylvanian Review of Administrative Sciences. 2012 April 21; 35:22-32.

5. Anyanwu JC, Erhijakpor AEO. Health Expenditure and Health outcomes in Africa. African Development Review. 2009 May; 21(2):400-433.

6. Heijink R, Koolman X, Westert GP. Spending more money, saving more lives? The relationship between avoidable mortality and healthcare spending in 14 countries. The European Journal of Health Economics. 2013; 14(3):527-38. Doi: 10.1007/s10198-012-0398-3.

7. Hanmer L, Lensink R, White H. Infant and child mortality in developing countries: Analysing the data for robust determinants. The Journal of Development Studies. 2003; 40(1):101-118. doi: $10.1080 / 00220380412331293687$.

8. Bein MA, Unlucan D, Olowu G, Kalifa W. Healthcare spending and health outcomes: evidence from selected East African countries. Afri Health Sci. 2017; 17(1):247-254.

9. Crémieux P-Y., Ouellette, P, and Pilon. C. Healthcare spending as determinants of health outcomes. Health Economics. 1999; 8(7):627- 
639.

10. Or Z. Exploring the effects of health care on mortality across OECD countries. Labour Market and Social Policy Occasional Papers. 46, Paris, Organisation for Economic Cooperation and Development. 2000a.

11. Or Z. Determinants of health outcomes in industrialised countries: a pooled, cross-country, time-series analysis. OECD Economic Studies: 30, 2000/1, Paris, Organisation for Economic Cooperation and Development. 2000b.

12. Nixon J, Ulmann P. The relationship between health care expenditure and health outcomes. European Journal of Health Economics. 2006; 7(7):7-18.

13. Babazono A, Hilman AL. A comparison of international health outcomes and health care spending. International Journal of Technology Assessment in Health Care. 1994; 10(3): 376-381.

14. Hassan SA, Zaman K, Zaman S, Shabir M. Measuring health expenditures and outcomes in SAARC region: Health is a luxury? Quality \& Quantity. 2014; 48(3):1421-1437. Doi: 10.1007/s11135013-9844-2.

15. Lippi G, Mattiuzzi C, Cervelin G. No correlation between health care expenditure and mortality in European countries. European journal of internal medicine. 2016; 32: 13-14.

16. Mackenbach JP. Health care expenditure and mortality from amenable conditions in the European community. Health Policy. 1991; 19(2): 245-255.

17. Burnside C, Dollar D. Aid, the incentive regime, and poverty reduction. The World Bank, Washington D.C. Macroeconomics and Growth Group. 1998.

18. Thornton J. Estimating a health production function for the US: some new evidence. Applied Economics. 2002; 34(1):59-62.

19. Kim K, and Moody PM. More resources, better health? A crossnational perspective. Social Science and Medicine. 1992; (34):837-42.

20. Akinkugbe $\mathrm{O}$, Mohanoe M. Public health expenditure as a determinant of health status in Lesotho. Social Work in Public Health. 2009; 24(1-2):131-147.

21. Bokhari FA, Gai Y, Gottret P. Government health expenditures and health outcomes. Health Economics. 2007; (16):257-73

22. Farahani M, Subramanian SV, Canning D. Effects of state-level public spending on health on the mortality probability in India. Health Econ. 2010; 19(11):1361-76.

23. Arun JV, Kumar D. Public health expenditure of BRICS countries - an empirical analysis. International Journal of Medical Science and Public Health. 2016; 5(11):4-7.

24. Bhalotra S. Spending to save? State health expenditure and infant mortality in India. Health Economics. 2007; 16:911-928.

25. Gupta S, Marijn V, Erwin R. Public spending on health care and the poor. Health Economics 2003; (12):685-96.

26. Zakir MV, Wunnava PV. Factors affecting infant mortality rates: evidence from cross-sectional data. Applied Economics Letters. 1999; 6:5, 271-273, Doi: 10.1080/135048599353203.

27. Filmer D, Pritchett L. The impact of public spending on health: does money matter? Social Science and Medicine. 1999; 49:1309-1323.

28. Berger CM, Messer J. Public financing of health expenditures, insurance, and health outcomes. Applied Economics. 2002; 17(34):2105-2113. Doi: 10.1080/00036840210135665.

29. Granlund D. The effect of health care expenditure on sickness absence. The European Journal of Health Economics 2010; 11:555-568. Doi: 10.1007/s10198-009-0213-y

30. Filmer D, Pritchett L. Child mortality and public spending on health: how much does money matter? World Bank Policy Research Working
Paper No. 1864 Washington: World Bank 1997.

31. Aìsa R, Clemente J, Pueyo F. The influence of health expenditure on longevity: a reconsideration. International Journal of Public Health. 2014; 59(5):867-875.

32. Xu K, Evans DB, Carrin G, Aguilar-Rivera AM, Musgrove P, Evans T. Protecting households from catastrophic health spending. Health Aff. 2007; 26:972-83.

33. Novignon J, Olakojo SA, Nonvignon J. The effects of public and private health care expenditure on health status in sub-Saharan Africa: New evidence from panel data analysis. Health Economics Review. 2012; 2:22. Doi: 10.1186/2191-1991-2-22.

34. Homaie RE, Vahedi S, Teimourizad A, Esmaeilzadeh F, Hadian M, Torabi PA. Comparison of the effects of public and private health expenditures on the health status: A panel data analysis in Eastern Mediterranean countries. International Journal of Health Policy and Management. 2013; (1):163-167.

35. Issa H, Ouattara B. The effect of private and public health expenditure on infant mortality rates: does the level of development matters? 2005 May [cited 2016 September 10]. Available from: http:// www.swan.ac.uk/economics/dpapers/2005/0502.pdf

36. Gani A. Health care financing and health outcomes in pacific islands countries. Health Policy and Planning. 2008; 24(1):72-81. Doi: 10.1093/heapol/czn044.

37. Panopoulou E, Pantelidis T. Convergence in per capita health expenditures and health outcomes in the OECD countries. Applied Economics. 2012; 3909-3920. Doi: 10.1080/00036846.2011.583222. doi.org/10.1080/00036846.2011.583222.

38. Bokhari FAS, Gai Y, Gottret P. Government health expenditures and health outcomes. Health Economics. 2007; 16(3):257-273.

39. McGuire JW. Basic health care provision and under-5 mortality: a cross-national study of developing countries. World Development. 2006; 34(3):405-425.

40. Shandra JM, Nobles J, London B, Williamson JB. Dependency, democracy, and infant mortality: a quantitative, cross-national analysis of less developed countries. Social Science and Medicine. 2004; 59(2):321-333

41. Marianne F, Leipziger D, Wodon Q, Yepes T. Achieving childhealth-related millennium development goals: the role of infrastructure. World Development. 2005; 33(8):1267-84. Doi: doi.org/10.1016/j. worlddev.2005.03.001.

42. Kessler D, McClellan M. Is hospital competition socially wasteful? Quarterly Journal of Economics. 2000; (115):577-615.

43. Glied S and Lieras-Muney A. Health inequality, education and medical innovation. NBER, working paper No 97382003.

44. Moore S, Teixeira AC, Shiell A. The health of nations in a global context: trade, global stratification, and infant mortality rates. Social Science \& Medicine. 2006; 63:165-178. doi: doi.org/10.1016/j. socscimed.2005.12.009.

45. Wagstaff, A, Cleason M. The millennium development goals for health: rising to the challenge. Washington, D.C. World Bank 2004.

46. Bredenkamp C, Mendola M, Gragnolati M. Catastrophic and impoverishing effects of health expenditure: new evidence from the Western Balkans. Health Policy Plan. 2011;6-21. Doi:10.1093/ heapol/ czq070.

47. Ekman B. Catastrophic health payments and health insurance: some counterintuitive evidence from one low-income country. Health Policy. 2007; (83):304-13.

48. Van Doorslaer E, O'Donnell O, Rannan-Eliya R, Somanathan A, Adhikari SR, Garg CC, et al. Catastrophic expenditures on health care in Asia. Health Economics. 2007; 8(16):1159-84. 
49. Wagstaff A, Van Doorslaer E. Catastrophe and impoverishment in paying for health care: with applications to Vietnam 1993-98, Health Economics. 2003; (12):921-34.

50. Xu K, Evans DB, Carrin G, Aquilar-Rivera AM, Musgrove P, Evans T. Protecting households from catastrophic health spending. Health Affairs. 2007; 2(26):972-83.

51. Irving M, Kingdom GG. Gender patterns in household health expenditure allocation: a study of South Africa. Institute of Education, University of London, 20 Bedford Way, London. 2008

52. Gao M, Yao Y. Gender gaps in access to health care in rural China. Economic Development and Cultural Change. 2006;(55):87-107.

53. Global Burden Diseases (GBD) and HALE Collaborators. Global, regional, and national disability-adjusted life-years (DALYs) for 315 diseases and injuries and healthy life expectancy (HALE), 1990-2015: a systematic analysis for the Global Burden of Disease Study 2015. Published by Elsevier Ltd

54. Buseh AG, Stevens PE, Bromberg M, Kelber ST. The Ebola epidemic in West Africa: Challenges, opportunities, and policy priority areas. US National Library of Medicine: National Institute of Health. 2014 January; 63(1) 30-40. DOI: 10.1016/j.outlook.2014.12.013.

55. Human Development Index, 2015. [Cited 2017 January 13]. Available from: http://hdr.undp.org/sites/default/files/2015_human_ development_report.pdf.

56. Sustainable development knowledge platform. Sustainable development goals. [Cited 2015 November 7] Available from: https:// sustainabledevelopment.un.org/topics.

57. Bongaarts J, Guilmoto CZ. How many more missing women? Excess female mortality and prenatal sex selection, 1970-2050. Population and Development Review. 2015; 41(2):241-69. doi: 10.1111/j.17284457.2015.00046.x.

58. Mustard CA, Kaufert P, Kozyrskyj A, Mayer T. Sex differences in the use of health care services. N Engl J Med. 1998; 338:1678-1683. Doi: 10.1056/NEJM199806043382307.
59. Bertakis KD, Azari R, Helms LJ, Callahan EJ, Robbins JA. Gender differences in the utilization of health care services. J Fam Pract. 2000; 49(2):147-152.

60. Forbes K, Rigobon R. No contagion, only interdependence: measuring stock market co-movements. Journal of Finance. 2002;(57):2223-2261.

61. Bein AM, Tuna G. Volatility transmission and dynamic correlation analysis between developed and emerging European stock markets during sovereign debt crisis. Romanian Journal of Economic Forecasting. 2015;18(2):61-80.

62. Wooldridge JM. Introductory econometrics: a modern approach. 3rd ed. South-Western: Cengage Learning International; USA. 2006.

63. Reyna OT. Panel data analysis fixed and random Eeffects using stata (v.4.2). Princeton University. 2007 December. [Cited 2017 May]. Available from: https://www.princeton.edu/ otorres/Panel101.pdf.

64. Baltagi BH. Econometric analysis of panel data. 3rd Ed. USA: Wiley \& Sons: 2005.

65. Bayati M, Akbarian R, Kavosi Z. Determinants of life expectancy in Eastern Mediterranean region: A health production function. International Journal of Health Policy and Management. 2013; 1(1):6571.

66. Akinci F, Hamidi S, Suvankulov F, Akhmedjonov A. Examining the impact of health care expenditures on health outcomes in the Middle East. N. Africa. Journal of Healthcare Finance 2014; 41(1):11-20

67. Cevik S, Tasar MO. Public spending on health care and health outcomes: cross country Comparison. Journal of Business, Economics \& Finance. 2013; 2(4)21-30. 